\title{
A DECISION-MAKING FRAMEWORK FOR IMPLEMENTING DIGITALISATION IN THE SOUTH AFRICAN TOOLING INDUSTRY
}

\author{
M.T. Dewa ${ }^{1 * \#}$, A.F. van der Merwe ${ }^{1}$ \& S. Matope ${ }^{1}$
}

\section{ARTICLE INFO}

Article details

Submitted by authors 16 Jan 2018

Accepted for publication 20 Oct 2018

Available online 10 Dec 2018

Contact details

Corresponding author

mnce2009@gmail.com

Author affiliations

1 Department of Industrial

Engineering, Stellenbosch

University, South Africa

\# $\quad$ Author was enrolled for a PhD in the Department of Industrial Engineering, Stellenbosch

University, South Africa

\section{DOI}

http://dx.doi.org/10.7166/29-4-1903

\section{ABSTRACT}

In this paper, a decision-making framework for implementing the concept of digitalisation within the South African tool, die, and mould-making (TDM) industry context is developed and employed. The purpose of this framework is to answer the following question: "Which digital technologies currently available on the market can be employed to improve the efficiency of shop-floor operations in the South African TDM industry?" An exhaustive literature study of existing digital technologies is conducted. Thereafter, TDM processes requiring digitalisation are identified through knowledge engineering. Based on the system requirements analysis, digital technologies relevant to the South African TDM context are then proposed.

\section{OPSOMMING}

'n Besluitnemingsraamwerk vir implementering van die konsep van digitalisering binne die Suid-Afrikaanse matrysmaak industrie is ontwikkel en toegepas. Die doel van hierdie raamwerk is om die volgende vraag te beantwoord: "Watter digitale tegnologieë, wat nou beskikbaar is, kan gebruik word om die rendement van werkswinkel bedrywighede in die Suid-Afrikaanse matrysmaak industrie te verbeter?" 'n Omvattende literatuurstudie van bestaande digitale tegnologieë is van stapel gestuur. Daarna is matrysmaak prosesse wat kan baat by digitalisering identifiseer. Op grond van die sisteemvereistes analise is digitale tegnologieë relevant tot die Suid-Afrikaanse matrysmaak konteks dan voorgestel.

\section{INTRODUCTION}

The production of tools, dies, and moulds (TDM) is a complex activity that requires a lot of expert knowledge and sound judgement. Due to the demand for customised and unique products, the process of tool-making requires great innovation, making it highly dependent on the craftsmanship of the toolmaker. The success of a project therefore depends on the experience and skill levels of the workers doing the job. This makes tool-making a skills- or people-driven exercise. The skills required in the TDM value chain include tool designing, project managing, toolmaking, cost estimating, and many more specialised roles. Schuh, Pitsch, Komorek, Schippers and Salmen [1] described the TDM industry as a knowledge-intensive and data-driven sector. During the fabrication of tools, dies, and moulds, many transactions that involve information exchange occur between toolmakers, their downstream customers, and their upstream suppliers, as illustrated in Figure 1. 


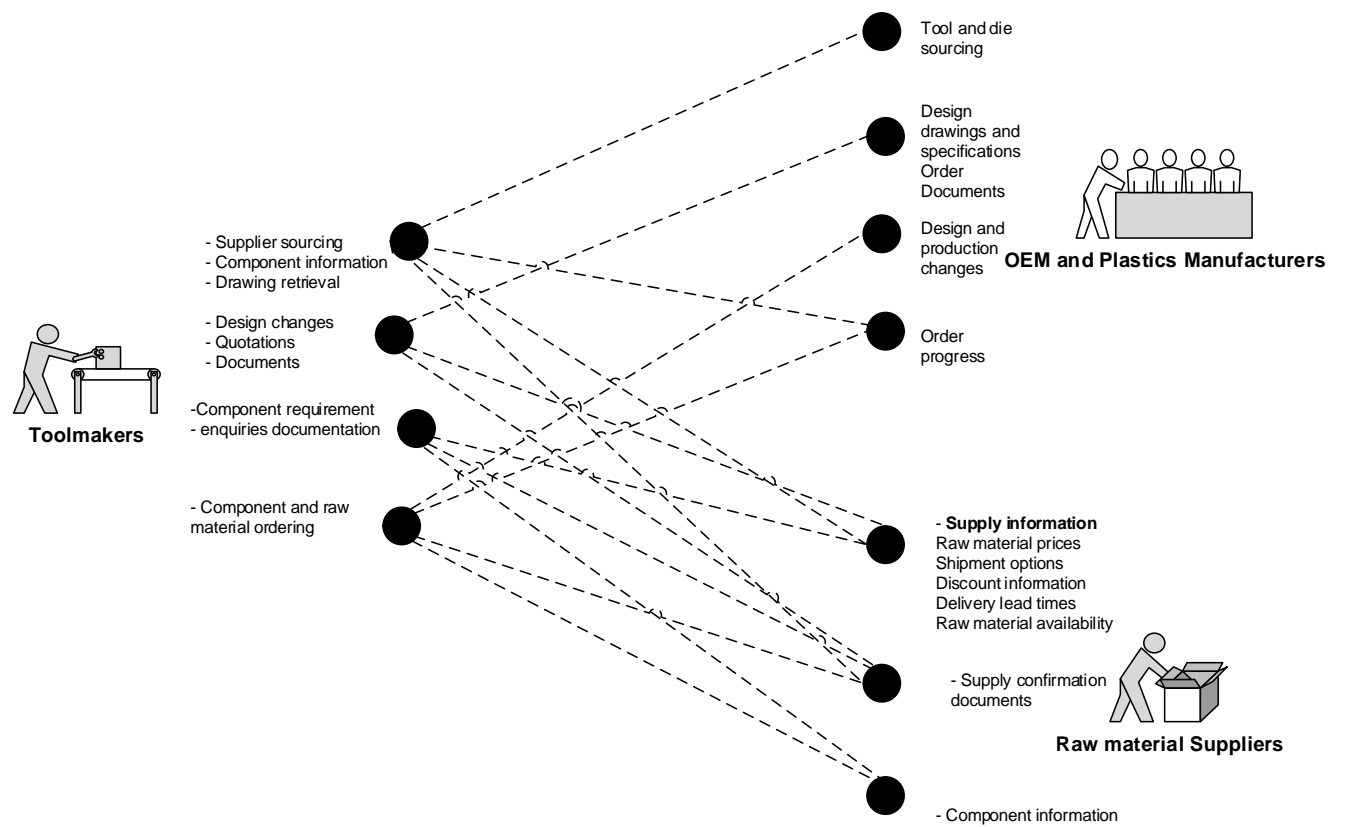

Figure 1: Transactions during order processing in TDM operations [2]

Due to the wide range of products it produces, the TDM industry is characterised by a huge variability of requirements and specifications for each final product. Figure 1 represents the nature of communication involved in processing orders in the TDM sector. A lot of production data is exchanged between toolmakers, their raw material suppliers, and their clients (usually overall equipment manufacturers [OEMs]). To arrive at an optimal decision, numerous enquiries and computations need to be established, making the process time-consuming and cumbersome. Thus the availability of real-time information is critical to the success of any tool production environment [3]. Having current manufacturing data at your fingertips is the first step for any TDM organisation to become a high-tech competitive enterprise in a highly global world. The future of TDM manufacturing lies in the development of information solutions that allow manufacturers to be more proactive, intelligent, and informed, while supporting the execution of timely decisions. The TDM industry in South Africa is a critical support industry to the broader manufacturing sector, bridging the gap between product development and series production. Records reveal that over 90 per cent of firms in the South African TDM sector are small family-owned businesses in the range of small, medium and micro enterprises (SMMEs) [4].

Recent results of the on-going benchmarking initiative in the South African TDM industry have shown that most observed firms struggle on the global market due to intense external competition and internal shortcomings [4]. One of the identified challenges was that of poor organisational shopfloor practices adopted by most observed TDM firms in South Africa [4]. The organisational shortfalls of the South African TDM sector are a sign of poor business or operational practices. According to Von Leipzig and Dimitrov [5], the results from the on-going benchmarking surveys clearly show that the initial and later stages of the tool production value stream are being neglected in some South African TDM firms. In their analysis, Von Leipzig and Dimitrov [5] went on to specify that the South African TDM sector is characterised by difficulties in data collection and manipulation. The question that arises is: "What can South African TDM firms do to overcome those data collection and manipulation shortcomings?"

A study by Schuh et al. [6] on the concept of 'fast forward tooling' identified nine critical success factors that tool-making firms can implement to improve their global competitive position. One of the factors suggested is that of 'digitalisation', which has the potential significantly to improve the competitiveness of a tooling enterprise, and so become the basis for other success factors. The concept has been promoted as having the potential significantly to improve the operational competitiveness of manufacturing enterprises [7]. In the study by Schuh et al. [6], digitalisation was suggested to have the potential of addressing data collection and manipulation shortcomings. With the recent growth in information, communication technology (ICT), such as Internet of Things (IOT) 
devices, it is now possible to apply the concept of digitalisation, thus improving the flexibility, agility, efficiency, and productivity of operations in a tooling environment [8]. According to Business Insider estimates, by the year 2020 about 20 billion devices will be connected to the internet, with 40 per cent of these being loT devices [9], as shown in Figure 2.

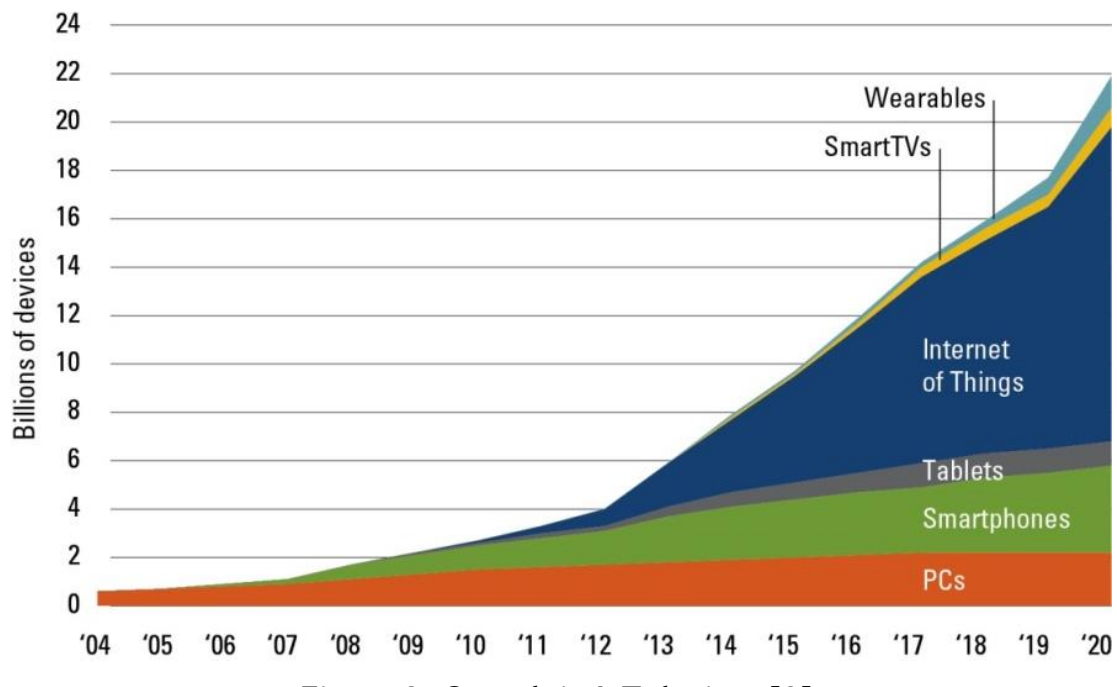

Figure 2: Growth in loT devices [9]

According to Schuh, Kuhlmann, Pitsch and Komorek [10], loT devices will greatly impact how toolmakers perform production in the $21^{\text {st }}$ century. These technologies will guide toolmakers to new opportunities for connectivity, real-time analytics, and automatic data capture, which will result in new manufacturing methodologies. The application of IoT or current ICT technology is yet to be fully explored in terms of its relevance in the digitalisation of shop-floor operations in the South African TDM industry. Thus the potential of digitalisation is yet to be comprehensively explored by South African tooling companies. This paper attempts to fill this gap through a systematic selection of technologies that can aid in the digitalisation of shop-floor operations in the South African TDM sector.

\section{LITERATURE REVIEW}

\subsection{Digitalisation}

In this section, the concept of digitalisation is further explored as a potential initiative to improve the competitiveness of TDM operations in the area of data collection. The benefits of digitalisation are outlined, and technologies supporting digitalisation are also explained, before state of the art research on digitalisation within the global tooling industry is shown. Justification is given as to why this concept is relevant in the tooling industry now.

\subsubsection{Concept of digitalisation}

Digitalisation can be viewed as the implementation of current ICT to improve production processes, efficiency, and productivity. The concept has been promoted as having the potential significantly to improve the competitiveness of manufacturing enterprises [7]. According to Stolterman and Fors [11], digitalisation or digital transformation refers to the changes associated with the application of digital technology in all aspects of human society [12]. The concept differs slightly from that of digitisation, which refers to the conversion of analogue or manual processes to digital ones. Brennen and Kreiss [13] defined the concept of digitalisation as "the adoption or increase in use of digital or computer technology by an organisation, industry or country". Unfortunately, the rate of adoption of digital technologies in the manufacturing sector has been slow, with most firms adopting a "wait and see' approach [14]. However, the companies that have implemented digital solutions have experienced success stories [7]. Therefore tool-making firms ought to view digital solutions as an opportunity rather than as a threat [8]. The limited success in adopting digital technologies has been attributed to various reasons that include high implementation costs and a lack of awareness [4]. Digitalisation is to be viewed as an on-going process, rather than as a one-stop destination, as firms 
ought continually to evaluate what is worth digitalising. This is mainly because digital technologies evolve on the market at a fast pace in a globalised world. To be successful, one has to keep up with current technological trends and pilot small solutions incrementally to inspire workers, while improving competitiveness.

\subsubsection{Scope of digitalisation}

The concept of digitalisation has been reckoned to apply to different scenarios and applications in the business world. The available literature records three different views of digitalisation: the process-level, the product-level, and supply-chain views. In the process-level view of digitalisation, new digital tools are adopted to streamline business activities and processes by reducing manual steps [12], while the product-level view focuses on the ability to turn existing products or services into digital variants, thus offering a competitive advantage over other tangible products [15]. The supply-chain view of digitalisation only focuses on the use of digital technologies to connect suppliers and customers, radically transforming business procedures through connectivity. Since this study focuses on the digitalisation of shop-floor operations in a tooling environment, only the processlevel view applies. One of the goals in process-level digitalisation is to ensure real-time availability of information for decision-makers within an organisation [16].

Figure 3 illustrates the scope of the processes involved when digitalisation occurs in a firm. The basis for digitalisation is the recording of data - and a lot of data is to be found in a manufacturing environment. The concept enables the recording of information from manufacturing processes and from serial production. After the data is collected, it is processed into smart data or information that is presented in a meaningful way for managers and decision-makers to make decisions. This permits the establishment of unique know-how or sustainable knowledge. As a result, a company will possess expert knowledge that can be used for future decision-making, and that may be commercialised.

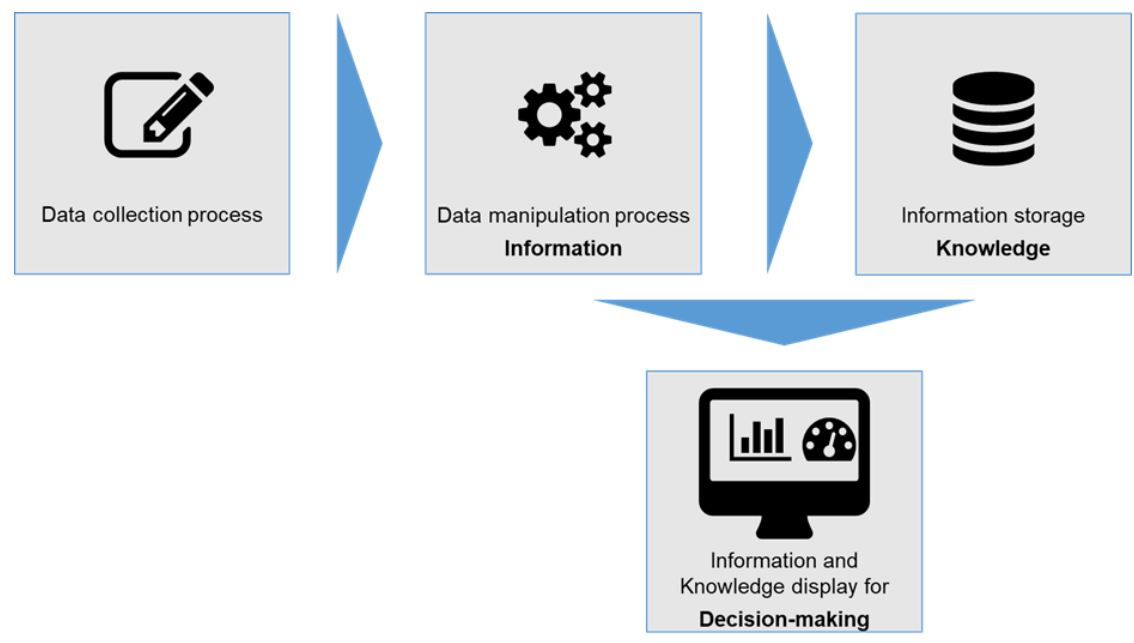

Figure 3: Digitalisation scope (concept adapted from [6])

During the implementation of digitalisation, companies should address a number of questions for the venture to be effective. These questions include:

1. Which business processes are likely to experience immense benefits from digitalisation?

2. What knowledge or information is required to make daily operational decisions?

3. Which data must be collected to generate the required information?

4. What are the sources of the required data?

5. Which digital technologies can be used for data collection, manipulation, and information display?

\subsection{Current digital technologies}

With the cost and power in computing dropping exponentially each year into the range of cents and milliwatts respectively, digital technologies are becoming common and ubiquitous. This section 
outlines some current technologies that can potentially improve shop-floor operations in the TDM industry.

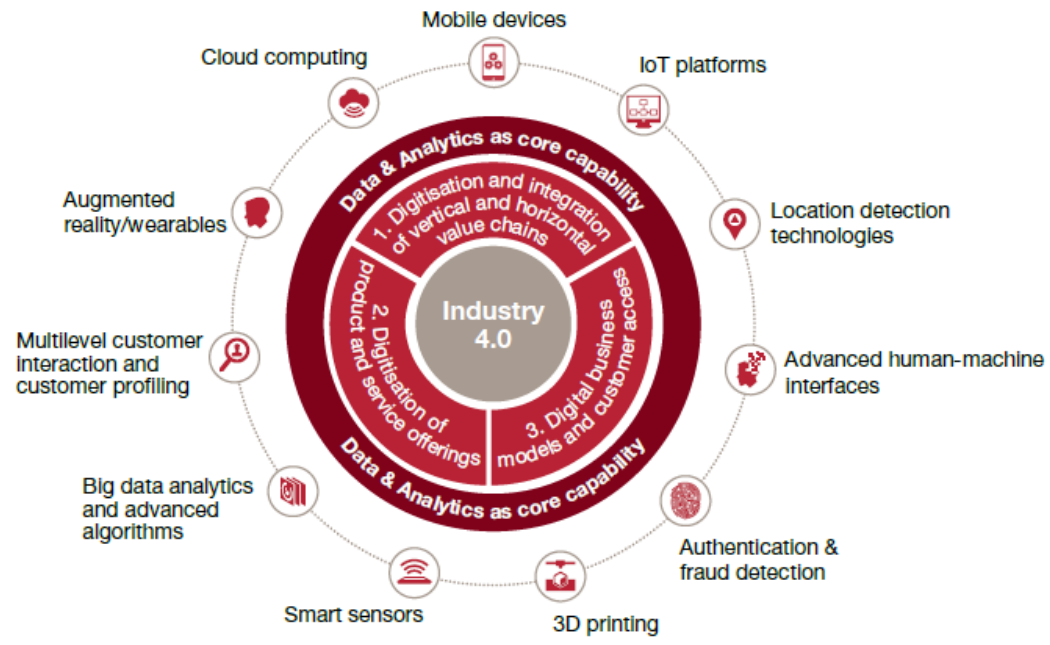

Figure 4: Industry 4.0 framework and supporting digital technologies [16]

The Industry 4.0 framework established by Reinhard, Jesper and Stefan [16] is used in this paper to formulate its theoretical framework. In this study, different classes of currently available digital technologies that can potentially improve manufacturing operations are outlined and used (Figure 4).

\subsubsection{Digital technologies for value chain integration}

Cloud computing platforms, loT networks, mobile devices, and wearables facilitate the integration of business processes, thus making firms adopt new models and ways of trading.

The loT is the network of physical objects around us that contain electronic components, software, sensors, and networking systems that allow these objects to exchange and acquire information. Thus an loT framework consists of everyday physical objects with attached sensors that send big data streams to the Internet for information analytics via a communication or networking channel [17]. To join this world of devices together in a more efficient way, loT platforms have emerged [18]. These are readily available online tools for linking sensors to the cloud, with analytics capabilities as well. These include the Google Cloud, Thingworx, Microsoft Azure, and Jasper (Cisco) platforms [19]. Although the industrial loT can greatly improve operational excellence in the TDM sector, little research is available to date on the application of the technology within the sector.

More recently, mobile devices such as smartphones and tablets have become ubiquitous in everyday life [20]. These gadgets have become readily available at low prices, causing a growth in their use in the $21^{\text {st }}$ century. Modern smartphones have become programmable. They also come with a growing number of embedded sensors, such as a digital compass, accelerometer, gyroscope, GPS, microphone, and camera [21]. As a result, the range of data these devices can handle is enormous, including text messages, GPS, barcodes, QR-codes, pictures or images, audio, and video [14]. These days, mobile devices can browse the Internet, making them easily part of a global network of other objects. Mobile data can be accessed anywhere, at any time, in near real-time [22]. Mobile devices are well-suited for applications in which data collection is done repeatedly and is conducted in a distributed way, and where a large percentage of the data types collected are quantitative in nature [23]. Consequently, mobile devices are a potential solution for repeated and distributed data collection within the TDM sector.

Wearables and augmented reality are two technologies that look poised to empower the worker of tomorrow to be extraordinarily efficient and productive through contextual computing capabilities [24]. These applications are used to maximise the contextual awareness of an individual through providing real-time information, which is fundamental for decision-making. The majority of applications for this technology exist in the medical field, where human monitoring systems for pulse rate, body temperature, and exercise habits have been developed [25], [26]. However, the major 
drawbacks in the adoption of this technology include the limited battery lifespan of devices, the design and aesthetics of wearables, data privacy and management, and interoperability among solutions and vendors [27]. The cost of implementing such technologies is very high, while the majority of the vendor-oriented integration issues remain unresolved [28]. However, there is little available in the literature on the application of wearable technology within the TDM sector.

According to Mell and Grance [29], cloud computing is a model for enabling ubiquitous, convenient, on-demand network access to a shared pool of configurable computing resources (e.g., networks, servers, storage, applications, and services) that can be rapidly provisioned and released with minimal management effort or service provider interaction. This model of technology is a broad field of study with numerous resources that allow the sharing of data over distributed systems. Google has the most commonly used cloud computing resources in the form of Google Drive [30]. Microsoft Azure is another commonly used platform for Windows users [31]. Cloud computing platforms have a wide use in many domains, including business [32], healthcare, and manufacturing [33]. Web-based technologies have been used in the tooling industry to facilitate collaborative quality management [34], inventory control [2], and decision support [35]. The strategy of collaborative manufacturing has been gaining popularity in the TDM industry [5], a sector characterised by intense global competition [4]. Toolmakers have realised the need to focus on their core competencies and narrow their scope of value addition, thus teaming up during the fabrication of parts. Value chain integration technologies discussed in this section have the potential to improve shop-floor operations. As a result, cloud computing platforms have been employed to facilitate the integration of toolmaking through web-based portals [36].

\subsubsection{Digital technologies for product and service offerings}

Smart sensors, customer profiling, and big data analytics software offer new product variants and services in the digital world. A number of technologies that enhance the interaction of customers with products and services that companies offer are emerging on the market [37]. These solutions allow customers to define the product design during the conceptualisation stage, and to order items online without having to visit a firm or store [38]. Application areas for this class of technology include the use of self-service technologies (SSTs) such as telephone banking, automated hotel checkout, and online investment trading, where customers produce services for themselves without assistance from firm employees. With the volume and speed of data generated by computers and the Internet growing exponentially each year, the field of big data has grown, and attracts much attention in academia [39]. The field involves the use of data streams for inferential decisionmaking. As a result, many domain applications for big data technology have emerged, including supply chain management [40], manufacturing [41], and healthcare [42]. A major drawback in the wide adoption of big data analytics technologies is the issue of data security [43]. As a result, there is not much work in the available literature on the application of big data technology within the TDM sector.

With the ability to embed intelligence in systems made easier in the $21^{\text {st }}$ century, smart sensors are also emerging on the market [44]. These devices can make decisions based on the data they obtain through instrumental recording. Smart sensors have been used widely in academia and in research, with applications in the transportation and logistics industry [45], manufacturing [46], security [47], and healthcare [48], among many other examples. Toolmakers use machinery and equipment with smart sensors as well, making this class highly applicable to the sector.

\subsubsection{Digital technologies for business models and customer access}

Location and detection technologies, together with advanced human interfaces, 3D printing, and authentication detection technologies are another class of current digital devices. With global positioning system (GPS) technology freely and readily available nowadays, the tracking of object position is now possible. In the early $19^{\text {th }}$ century, barcode technology was commonly employed to record and communicate locational information for objects. However with the advancement of electronic gadgets, radio frequency identification (RFID) technology is also growing in use in the manufacturing sector [49]. These technologies allow the automatic identification (Auto ID) and tracking of objects while collecting specific data of parts moving in an environment [50]. Location detection technologies, such as RFID devices, are known to have many applications in supply-chain related problems, such as creating an loT framework [51], distributed manufacturing control [52], and mass customisation production [53]. The major drawbacks in the implementation of RFID technology have been as a result of proximity challenges, the effect of metal and water on RFID waves [54], and the high cost of implementation [51]. Part flow and identification is becoming critical in tool-making operations; thus RFID technologies may improve the competitiveness of the 
latter. Due to high implementation costs, SMMEs (such as tooling firms) rarely use these technologies on the shop floor. With the growth of embedded sensors in industrial equipment, human-machine interfaces for the real-time analytics of machinery performance have become a current reality [50]. Advanced human-machine interfaces are common on current industrial machines with numerous applications, including motion study [55] and manufacturing [56]. The high rate of cybercriminal activities and the need for security in specific fields make authentication and fraud detection technologies critical. The retail payments have the highest use of these technologies [57]. Other applications are found in Internet banking [58] and security systems [59]. Rapid prototyping has become a key stage in the product development cycle, and 3D printers have emerged on the market to fill this gap. Their use has been broad in the fields of construction [60], manufacturing [61], and medicine [62]; [63]; [64]; [65]; [66]. However, 3D printing technology does not address data collection and manipulation challenges, as it focuses on prototyping. As a result, this technology class was not used in the analysis.

The next section discusses the state-of-the-art field of digitalisation. Models and methodologies employed in the digital transformation of operations will be explored for the purpose of selecting an appropriate approach for the study. The application of digitalisation concepts in the TDM industry to date will also be reviewed.

\subsection{Research problem}

Although the availability of digital technologies has increased exponentially in the $21^{\text {st }}$ century, there is a slow industrial adoption in manufacturing companies, especially by SMMEs [67]. One reason that these production firms tend to shy away from the digitalisation concept may be a lack of appreciation of the benefits of implementation. Some firms view any digitalisation attempt as costly and as causing negative future implications for shop-floor operations. Consequently many firms follow the 'watch and see' approach [14]. Due to the vast diversity of operations and products in the TDM industry, there are no complete or standard digital solutions on the market for toolmakers. Eventually, tool-making firms develop their own personalised solutions [8]. As a result, the potential benefits of digitalisation are yet to be comprehensively explored by South African tooling companies. This paper attempts to employ a systematic method of process analysis and selection of appropriate technologies for the digital transformation of operations on the tool room shop-floor, while assessing its applicability in the South African TDM sector. To achieve this, different methods for the digitalisation of production systems are analysed for the purpose of selecting the appropriate method applicable for tooling operations. Thereafter the system requirements are derived, and appropriate technologies are selected.

\section{SYSTEMATIC REVIEW OF DIGITALISATION METHODOLOGIES}

The digitalisation of different parts of business operations to support workers results in the development of digital assistance systems (DAS) [68] and technical assistance systems (TAS) [69]. Hinrichsen, Riediger and Unrau [70] defined an assistance system as a technical system that receives and processes information from its environment in order to support people carrying out their tasks. While DAS are computer systems that organise and present information in a way that supports operator decision-making [71], TAS are able to perform human physical tasks. The conceptualisation of the system requirements is usually the first crucial stage in developing DAS [72]. The need for the DAS must be established for the technical requirements to be generated [68]. As a result, the success of the design process depends on the selection and adoption of relevant structured methodologies for defining requirements [73]. This makes the digitalisation of production processes a challenging exercise that requires a strategic and systematic approach [74]. Unfortunately, the current literature lacks sufficient information on models or methodologies for the strategic digitalisation of processes [75]. Some researchers have identified gaps in the available literature about approaches to the systematic identification of information that users need for the appropriate selection of technologies and development of assistance systems ([76], [77]). While the technical digital instruments are well-known (as shown in section 2.2), the steps required in bringing about digital transformation remain broadly unclear. This section focuses on comparing the most current major methodological developments in the design and development of DAS. The comparison will aid in the selection of the appropriate design approach (methodology), which can aid in the digitalisation of shop-floor operations in the South African TDM industry.

To understand fully the concept of assistance systems and methodologies developed to date, a systematic literature review was conducted on the Scopus and Web of Science search engines. To 
avoid an ad hoc list of publications, the search filters were set using the theme phrases 'assistance systems', 'design of digital assistance systems', 'design of technical assistance systems', 'design of worker information systems (WIS)', and 'ICT implementation methodologies'. To obtain the most current work in the field, the search was limited to journal and conference publications between 1995 and 2018. The initial search yielded 12304 articles. After a thorough analysis, only 60 relevant publications were used in the synthesis.

According to Geiser [78], four interdependent models - task, user, interaction, and environment can be used, and should be distinguished when designing DAS. These models or approaches support the process of deriving requirements and roughly conceptualising an assistance system. The task model helps to identify the processes or decisions that can be supported by DAS. Figure 5 illustrates the different aspects that each model addresses during the conceptualisation of DAS.

A task-centred approach focuses on the relationship between characteristics of assembly tasks, the qualitative and quantitative evaluation of their complexity, and the derivation of requirements for digital assistance systems [79]. The task model helps the developer to identify processes or decisions that require the support of an assistance system. This is achieved by listing all the tasks contributing to the process, questioning users on the tasks that pose problems, and observing workers while they execute tasks [78]. Furthermore, specific characteristics can be used to determine the tasks that require support. Task-based approaches (such as the planning and evaluation model by Hold et al. [77]) make use of quantitative data collection and analysis methods, like the methods time measurement methodology that helps to improve system productivity while reducing operational costs. The approach can also give results on the economic feasibility of the developed DAS. However, a major shortcoming for the task-centric approach is that human factors such as safety and ergonomic needs can easily be overlooked in the derivation process, thus compromising on the acceptance of the DAS by operators. The task-centric approach is also well-suited for assembly tasks where there is a specific scope of operations. Manual assembly operations usually entail set-up, handling, joining, controlling, adjusting, and auxiliary tasks [70]. Task-based approaches are therefore difficult to implement in contexts where the product-mix is very wide, resulting in numerous complex tasks.

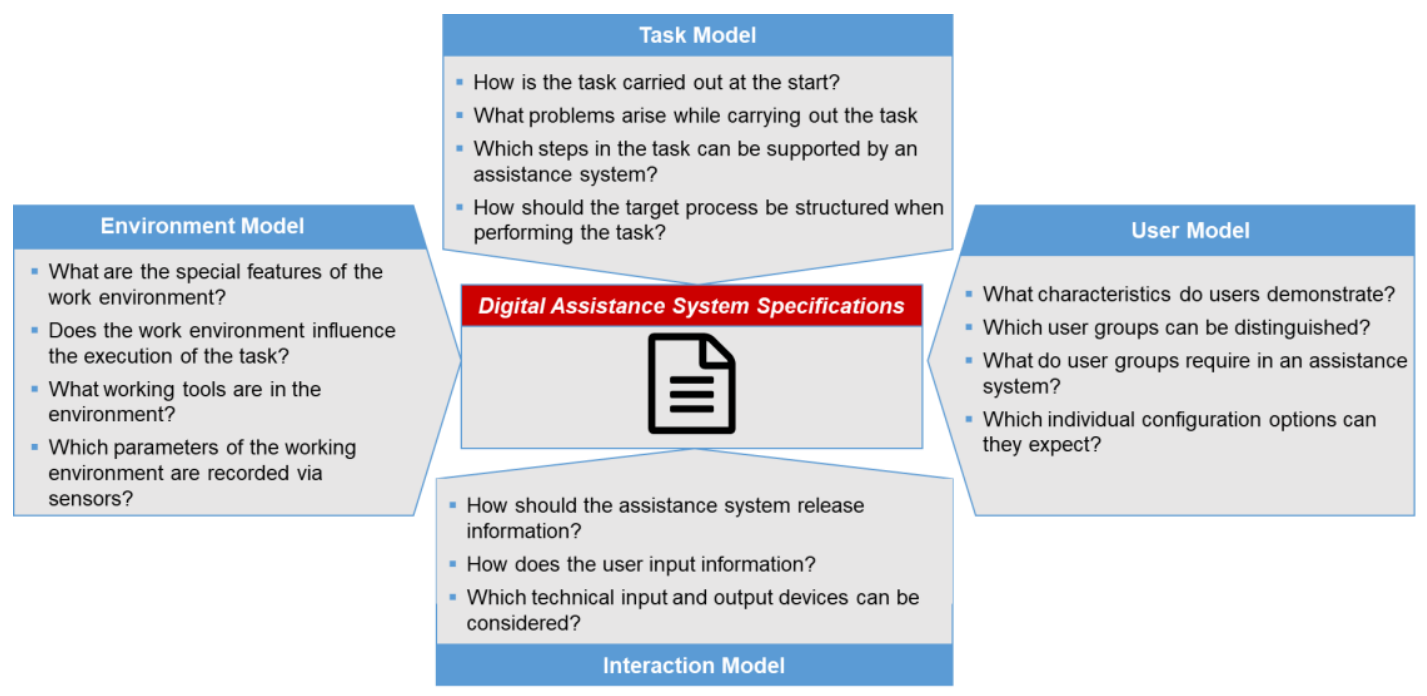

Figure 5: Model approaches for digitalisation [78]

While the task model focuses on business processes, the user model can guide the DAS developer to identify system users with the aim of distinguishing user groups. A user- centred approach focuses on employing user groups to inform the requirements of a DAS, based on their specific needs and characteristics [80]. This is crucial, as some users may not require DAS to support their operations; and different operators may have different needs they require from DAS. User-centric approaches (such as the worker participative model by Kleineberg, Eichelberg and Hinrichsen [81]) employ a strategy that requires consistent consultation with system users. User-centered approaches have been successfully implemented to develop assistance systems in the domains of transportation systems [82], healthcare systems [83], and environmental monitoring systems [84]. Since they 
employ human factor engineering principles, the acceptance and implementation of the final solution is enhanced [85]. Furthermore, human factors like safety and ergonomic needs are catered for in the early stages of the development process. This is crucial, since the user-friendliness and design interface of the technical devices employed in the DAS are a key factor to the ease of use of the application. Consequently, user-based approaches significantly reduce operator training times, thus improving organisational productivity. A major shortfall of the user- based approaches is that, since the data collection and analysis approach is purely qualitative, key quantitative factors such as productivity cannot be measured. As a result, the user-based approach cannot account for the economic use of the developed assistance system.

System users (for example, assembly operators) may have different system requirements. As a result, how each group interacts with DAS with regard to input and output information may differ. The interaction model guides the developer in deriving required user experience with the new technologies. The optimal technologies that fit the derived specification can therefore be selected, tested, and implemented [85].

In some cases, users may require external environmental input parameters, such as pressure and temperature, to be reckoned by the DAS. The environmental model defines how the system automatically detects these parameters through digital sensors [86],[87]. However, unlike other approaches, the environmental model is not a mandatory part of all DAS, as it is only required when context-specific data must be captured via sensors (as per requirements).

According to Lusic et al. [88], the implementation and configuration of worker information systems (WIS) or DAS depends on company specific boundary conditions. As a result, to define the application of digitalisation in the context of the tool-making industry, it is imperative that it is adapted to industry-specific characteristics [8]. Due to the customer specific products demanded in the TDM sector, the number of product variants and complexity of assembly operations increases. As a result, employing a task-based approach for the digitalisation of processes becomes difficult. The userbased approach is therefore selected as a more appropriate strategy to digitalising tool-making operations. The methodology should entail analysis of the tool room functions or users requiring digitalisation, the participative derivation of the toolmakers' requirements, and the design and configuration of the required technical instruments. This is important because only when the toolroom workforce view the assistance system as an asset can they actively engage in using it; a bottomup approach will improve the acceptability and implementation levels.

\section{RESEARCH METHODOLOGY}

This section outlines the research design and methods used in the study. According to Krishnan, Pujari and Sarkar [89], a systematic approach that involves analysis, design, development, and testing is required to achieve the digital transformation of a business's operations. This design strategy entails analysis of the current state of an industry, identification of processes requiring improvement, and careful selection of appropriate technologies to bring about the digital transformation. Based on the review in section 3, a user-based approach was employed with the knowledge engineering methodology used in the study.

\subsection{Knowledge engineering}

To achieve the goal of deriving the system requirements through analysis, the method of knowledge engineering was employed. Knowledge engineering involves the derivation of expert knowledge within a specific domain or area through consistent interaction with field experts in that area [90]. During this stage, specific selected experts in the Western Cape Province TDM industry were frequently visited. During the visits, semi-structured, one-on-one interviews were used to collect data.

The Delphi or expert-opinion method was used in the careful selection of the field experts in the TDM industry. Authorities in the Western Cape tooling industry assisted in recommending specific experienced tool-making personnel. The experts' knowledge of processes that require digitalisation and the key parameters to consider were derived from these interviews. These findings would be used for the development of a digital blueprint of the system functionality for the envisaged solution. In other words, the responses from the interviewed experts helped to establish the required system features. 


\subsubsection{Rationale for knowledge engineering methodology}

The knowledge engineering methodology was chosen because opinion-based qualitative data on field knowledge in tooling was required. According to Hall [91], the methodology is effective in acquiring expert knowledge in a domain or field for the purpose of building an expert system. Semi-structured interviews were conducted with five different experts in the tooling industry. In a semi-structured interview, the researcher not only prepares questions to guide the data collection process, but also allows for flexibility in the discussion with the respondent. As a result, new questions can be designed and used during the conversation [92]. Interviews are an appropriate tool for obtaining opinion-based data. Interviews reap benefits because they allow for qualitative opinion-based reasons to be derived from the respondents [92]. A semi-structured approach was used so that the flexibility of the interview sessions was improved, and to allow for more information to be collected during discussions. However, interviews have limitations because they cannot give quantitative results. With a user-based approach being employed, the results obtained in the study will be purely qualitative in nature. The results from interviews are purely subjective and opinion-based. Interviews also take a lot of time to conduct, and so only a small sample size can be used. To keep the responses flexible and to obtain more information, a semi-structured approach was used. In some instances, the expert would demonstrate some concepts, using examples to enable a better understanding.

\subsubsection{Data collection strategy}

During the visits, the questions shown in Table 1 were used to derive the information required for technology selection. Since a user-based approach was selected (as discussed in section 3 ), the basis for the questions was derived from a user-based model suggested by Geiser [78] (Figure 5). This model requires the identification of users who will benefit from the introduction of digital technologies. Second, the identified users define the processes (in their scope of work) that can benefit immensely from digitalisation, and the parameters associated with each process. Finally, the identified processes and user needs are used to select the appropriate digital technologies.

Table 1: Interview questions and purpose

\begin{tabular}{|c|l|l|}
\hline Number & Interview question & Purpose of question \\
\hline 1 & $\begin{array}{l}\text { Which user groups or functions in a tooling environment } \\
\text { can benefit the most from using digital technologies? }\end{array}$ & $\begin{array}{l}\text { User group or function, and } \\
\text { process identification }\end{array}$ \\
\hline 2 & $\begin{array}{l}\text { For each identified user group (in question 1), which } \\
\text { processes (within their scope of work) require digital } \\
\text { technology support? }\end{array}$ & $\begin{array}{l}\text { User needs and } \\
\text { specifications identification }\end{array}$ \\
\hline 3 & $\begin{array}{l}\text { Given the characteristics of each digital technology, which } \\
\text { digital tools can improve the identified processes (in } \\
\text { question 2)? }\end{array}$ & $\begin{array}{l}\text { Digital technology class(es) } \\
\text { identification }\end{array}$ \\
\hline
\end{tabular}

Due to the wealth of information obtained quickly during the interview sessions, the researcher would make an audio recording of some interview sessions (after obtaining the respondent's consent). This would help in capturing all responses without missing anything, as the researcher would listen to the sessions after the interview and record all missed points. Both the interview responses and the audio recordings were stored on devices that remained locked away during the course of the study. This was done to ensure the security of the data obtained.

\section{RESULTS AND DISCUSSION}

This section outlines the major research findings for the study. The method of knowledge engineering was employed. Field experts from five different tool-making firms were interviewed to obtain results on:

- $\quad$ Functions or users that can benefit from digitalisation;

- Tool-room processes that can experience significant improvement through digitalisation; and

- The technologies that can be used to support identified processes while fulfilling user needs.

The five experts visited were mainly from injection mould design and press metal tool production specialist firms within the Western Cape Province TDM sector and the plastics manufacturing industry. The mean number of employees for the observed population of companies was 10.4. The specific number of toolmakers in each of the visited firms is shown in Table 2 . The names of the firms are not given, to abide by the academic ethics code of conduct. The tooling expert from 
company D had the greatest experience (with 40 years' experience in the tooling industry), as shown in Table 2. The average experience was determined to be 28.6 years.

Table 2: Experts' experience in years

\begin{tabular}{|l|c|c|c|c|c|}
\hline $\begin{array}{l}\text { Expert from } \\
\text { company }\end{array}$ & A & B & C & D & E \\
\hline $\begin{array}{l}\text { Number of } \\
\text { toolmakers in } \\
\text { company }\end{array}$ & 9 & 4 & 7 & 24 & 4 \\
\hline $\begin{array}{l}\text { Number of experts } \\
\text { interviewed per } \\
\text { firm }\end{array}$ & 1 & 1 & 1 & 1 & 1 \\
\hline $\begin{array}{l}\text { Experience of the } \\
\text { expert (years) }\end{array}$ & 19 & 28 & 23 & 40 & 33 \\
\hline
\end{tabular}

\subsection{Identified functions and processes}

The experts who were visited were questioned about which tooling functions impacted greatly on the due date reliability or speed of a project. These findings were in response to the first interview question, as shown in Table 1. The experts all alluded to the following critical functions:

- Tool design

- Cost estimation

- $\quad$ Project management - planning, scheduling, and control

- $\quad$ Production

It was therefore concluded that improving the data collection in the domains of design, cost estimation, process planning, and production functions would significantly improve business operations in a tooling environment. The process of tool, die, or mould design is fundamental to the delivery lead time within the TDM sector. A lack of proper design technologies, such as computeraided design (CAD) and computer-aided manufacturing (CAM) software, can compromise due date conformance [4]. With the use of a proper design depository, the production cycle times are significantly improved, thus reducing manufacturing lead times.

The cost estimation function was deemed crucial because research has shown that, in the mouldmaking industry, usually less than 10 per cent of all offers turn into orders ([93]; [94]; [95]; [96]). Thus accurate and timely cost estimation for tool, die, and mould production is a key attribute in sustaining global competitiveness. Due to the skill shortages experienced by the South African TDM industry, the majority of tool-making firms take a long time to quote a job. Furthermore, results from benchmarking exercises of these firms have shown that the majority of quotes that are generated lack accuracy because of the methods employed. For effective and timely cost estimation, the parameters to be considered must be known, together with the decision heuristics to be followed.

Project management of orders in a tooling environment is another complex task requiring great skill and expertise. This is mainly because operational disturbances, such as rush orders or breakdowns, can complicate the life of project managers. Initially prepared process plans and schedules can easily become invalid, needing continual revision [97]. For a project to finish within the budgeted time, efficient project management techniques should be employed. All value-adding activities in a tool room need careful procedure conformance and great skill. As a result, administrative work on the shop floor can be a nightmare if it is not well-designed and well-managed. The time taken to do each operation is a critical parameter, as it will help in giving feedback on the progress of the order. Furthermore, knowledge of manufacturing task times serves as a valuable input during the cost estimation of the same job in the future. After establishing these system functions, the key parameters for each function were derived. Since labour-related costs are the greatest contributor to the overall tool cost, monitoring and control of production time is crucial. One of the consulted experts indicated that over 60 per cent of the tool's costs is labour-related.

\subsection{User needs and specifications}

The interaction with the experts also included deriving the system requirements for a digital solution. These requirements were drawn as a response to the second interview question, illustrated 
in Table 1. The five features (user specifications) described in this section were highlighted by the respondents (the experts).

\subsubsection{Collaborative manufacturing}

Due to globalisation, the manufacturing of products is no longer a local activity done by a single company, but rather a distributed venture as more firms realise the need to improve their flexibility and agility. All respondents indicated that the different roles participating in any project can be situated in different locations. Thus the first system requirement derived is the capability to facilitate distributed sharing of information over long distances between different role players in the tooling industry [98]. Furthermore, tooling firms need to be linked continually to their suppliers and customers for seamless information transfer. Collaborative manufacturing has been proposed as a key strategy to improve the competitive position of a tool-making firm.

\subsubsection{Flexibility}

Another feature that respondents advocated for was that of flexibility: the ability to respond to internal and external changes. This is mainly because, during a tooling project, events rarely go as expected [99]. The respondents all indicated the possibility of production plans being disrupted by disturbances in the production environment. As a result, digitalisation should enable the ability to trigger alerts for events that lead to shop-floor risks before they disturb operations and negatively impact customer experiences.

\subsubsection{Ease of data collection}

The developed solution should also facilitate ease of data collection. Manual data collection requires highly intense administrative work that can be taxing to a toolmaker with other responsibilities. As a result, the duty can be postponed to later stages. The digital solution should thus simplify the data collection process.

\subsubsection{Creation and preservation of expert knowledge}

Tool-making firms need to abide by an established quality management system standard that requires compliance in preserving the historical records of orders. Due to the rigour involved in manual data collection methods, the majority of firms have failed to keep records of their work. The solution developed should thus enable the preservation of orders, while helping to preserve expert knowledge. With the decline in the number of skilled toolmakers in the country, preserving expert knowledge will serve to ensure that young tool-makers make better decisions for generations to come. The above features suggest that toolmakers need a digital solution with holonic characteristics [98]. According to Wyns [100], applications like these promise the benefits that a holonic organisation provides to living organisms and societies: stability in the face of disturbances, adaptability and flexibility in the face of change, and the efficient use of available resources in a distributed environment.

\subsubsection{Real-time tracking of orders}

The ability of OEMs to monitor the progress of their jobs (processed in a TDM firm) has become imperative to win orders. As a result, an emerging requirement is the ability to monitor the progress of tasks for on-going projects and to obtain real-time feedback on their current status.

\subsubsection{Generation of real-time reports}

To facilitate real-time tracking, reports need to be generated for tool room managers to make timely decisions. The respondents indicated examples of these reports to include information on:

- $\quad$ Actual cost incurred per job versus the estimated cost;

- $\quad$ Actual time spent in doing tasks versus the estimated time; and

- $\quad$ Any disturbances emerging to hinder order progress.

When managers are equipped with this information, timeous interventions can be made to improve operational productivity and efficiency.

\subsection{Digital technology selection}

The framework of Industry 4.0 technologies, illustrated in Figure 4 (and cited in the literature), was used in the selection of the relevant technologies (see section 2). This was conducted in response to the third interview question (illustrated in Table 1) on the selection of the appropriate technologies to meet the derived requirements. Table 3 provides a legend for the symbols used in the analysis. As illustrated in Table 4, cloud computing platforms and mobile devices are possible digital solutions. 
Table 3: Legend for Table 4 (selection framework)

\begin{tabular}{|c|c|}
\hline Symbol & Meaning of the symbol \\
\hline$\circ$ & Technology is not applicable in meeting the derived system requirement \\
\hline$\checkmark$ & Technology is applicable in meeting the derived system requirement \\
\hline
\end{tabular}

Table 4: Digital technology selection framework

\begin{tabular}{|c|c|c|c|c|c|c|c|}
\hline \multirow[b]{2}{*}{$\begin{array}{c}\text { Available } \\
\text { digital } \\
\text { technologies } \\
\text { (section 2.2) }\end{array}$} & \multirow[b]{2}{*}{$\begin{array}{l}\text { Application } \\
\text { domain }\end{array}$} & \multicolumn{6}{|c|}{ Derived system requirements (from interviews with tooling experts) } \\
\hline & & $\begin{array}{c}\text { Collaborative } \\
\text { or } \\
\text { distributed } \\
\text { data } \\
\text { collection }\end{array}$ & $\begin{array}{l}\text { Flexibility in } \\
\text { the face of } \\
\text { changes }\end{array}$ & $\begin{array}{l}\text { Ease in } \\
\text { data- } \\
\text { collection }\end{array}$ & $\begin{array}{c}\text { Preservation } \\
\text { of } \\
\text { knowledge }\end{array}$ & $\begin{array}{l}\text { Real-time } \\
\text { tracking } \\
\text { of orders }\end{array}$ & $\begin{array}{l}\text { Genera- } \\
\text { tion of } \\
\text { reports } \\
\text { and } \\
\text { real- } \\
\text { time } \\
\text { alerts }\end{array}$ \\
\hline loT platforms & $\begin{array}{c}\text { Process } \\
\text { level }\end{array}$ & $\checkmark$ & $\checkmark$ & $\circ$ & 0 & $\checkmark$ & $\circ$ \\
\hline $\begin{array}{c}\text { Location } \\
\text { detection } \\
\text { technologies }\end{array}$ & Supply chain & $\circ$ & $\circ$ & 0 & $\circ$ & $\checkmark$ & 0 \\
\hline $\begin{array}{c}\text { Advanced } \\
\text { human } \\
\text { machine } \\
\text { interfaces }\end{array}$ & Supply chain & ○ & ० & ○ & $\circ$ & $\circ$ & ० \\
\hline $\begin{array}{l}\text { Authentication } \\
\text { and fraud } \\
\text { detection } \\
\text { technologies }\end{array}$ & Process level & ○ & ० & $\circ$ & $\circ$ & $\circ$ & $\circ$ \\
\hline Smart sensors & Product level & o & $\circ$ & 0 & 0 & $\checkmark$ & $\circ$ \\
\hline Mobile devices & $\begin{array}{c}\text { Process } \\
\text { level }\end{array}$ & $\checkmark$ & $\checkmark$ & $\checkmark$ & $\circ$ & $\checkmark$ & $\checkmark$ \\
\hline $\begin{array}{c}\text { Big data } \\
\text { analytics and } \\
\text { advanced } \\
\text { algorithms }\end{array}$ & $\begin{array}{l}\text { Process } \\
\text { level and } \\
\text { product } \\
\text { level }\end{array}$ & $\circ$ & ○ & $\circ$ & $\circ$ & ० & ○ \\
\hline $\begin{array}{c}\text { Multilevel } \\
\text { customer } \\
\text { interaction } \\
\text { and customer } \\
\text { profiling } \\
\text { technologies }\end{array}$ & Supply chain & $\circ$ & $\circ$ & ○ & $\circ$ & $\circ$ & $\circ$ \\
\hline $\begin{array}{c}\text { Cloud } \\
\text { computing } \\
\text { platforms }\end{array}$ & Process level & $\checkmark$ & $\checkmark$ & 0 & $\checkmark$ & $\checkmark$ & $\checkmark$ \\
\hline $\begin{array}{l}\text { Augmented } \\
\text { reality } \\
\text { wearables }\end{array}$ & Process level & 0 & $\circ$ & $\circ$ & $\circ$ & $\checkmark$ & $\circ$ \\
\hline
\end{tabular}

As shown in Table 4, a web-based mobile digital solution can help to address the derived system requirements. Furthermore, loT devices also have the potential to improve real-time data collection and tracking of events in a tooling environment.

\section{CONCLUSION}

Assistance systems (both digital and technical) in manufacturing have been developed and implemented to support manual tasks. As discussed in section 3, methodologies for developing assistance systems have been developed to support manual assembly systems in different contexts. As a result, work highlighting approaches applicable to scenarios with more operations in manufacturing (for example, downstream operations such as packaging, or some tooling processes) remains lacking in the available literature. The task-centric and user-centric approaches to developing DAS are the most common methodologies implemented in the models discussed earlier (see Figure 5). The developer of the DAS can either compare tasks or use them as a basis to derive requirements in the digitalisation process, or use system users to inform their needs on the tasks, interaction options, and possibly the environmental requirements that the DAS should address.

To define the application of digitalisation in the context of the tool-making industry, it is imperative that it is adapted to industry specific characteristics [8]. Due to the customer-specific products that are demanded in the TDM sector, the number of product variants and the complexity of assembly operations increase. As a result, employing a task-based approach to the digitalisation of processes 
becomes difficult. Furthermore, manual assembly operations usually only make up less than seven per cent of the entire TDM value chain operation. Consequently, the user-based approach was selected as a more appropriate strategy for digitising tool-making operations. This is important, because only when the tool-room workforce view the assistance system as an asset can they actively engage in using it; a bottom-up approach will thus improve the acceptability and implementation levels. Based on this analysis, as provided in section 3, a user-centric approach was selected to derive DAS needs in a TDM environment. This approach involved:

- $\quad$ identification of user groups (workers) requiring digital assistance;

- $\quad$ identification of processes that each user group deemed needed digitalisation; and

- $\quad$ derivation of digital technologies that can support the identified processes (see Table 1)

The knowledge engineering methodology was employed in the study through interviews of five field experts in the South African tooling sector. Shop-floor workers who perform the functions of design, cost estimation, scheduling, and production were identified as the user-groups requiring digital support, due to the complexity of data collection experienced in these functions.

Based on the derived requirements from these user-groups, mobile and cloud computing technologies were identified as having the potential to facilitate the digitalisation of South African TDM shop-floor operations. One emerging requirement in the TDM industry is the need to track partflow during production. RFID technology has the potential to fulfil that requirement, as discussed in the literature review (section 2). The major drawback in the use of RFID technology is the huge capital investment required for such a project. Future work can thus be done on how locational data can be digitalised using RFID technology in the South African TDM industry. Toolmakers can also develop web-based mobile solutions to support the integration of their value stream processes [101]. This paper aids in informing future work on the integration of digital technologies in the TDM industry in an efficient way.

\section{REFERENCES}

[1] Schuh, G., Pitsch, M., Komorek, N., Schippers, M. \& Salmen, M. 2014. Cutting manufacturing failure costs in the tool and die industry by implementing a knowledge transfer system to avoid and correct mistakes more effectively. Procedia CIRP, 16, pp. 80-85.

[2] Dewa, M.T., van der Merwe, A.F., Matope, S. \& Nyanga, L. 2014. A web-based holonic inventory management system for tool and die workshop operations. Proceedings of $44^{\text {th }}$ International Conference on Computers and Industrial Engineering, pp. 14-29. Istanbul, Turkey.

[3] Dewa, M.T., Mhlanga, S., Masiyazi, L. \& Museka, D. 2013. Design of a finite capacity scheduling system for bakery operations (flow shop environment). International Journal of Innovative Research in Science, Engineering and Technology, 2(11), pp. 6631-6640.

[4] Dewa, M.T., van der Merwe, A.F. \& Matope, S. 2015. Towards a competitive South African tooling industry. International Journal of Social, Behavioral, Educational, Economic, Business and Industrial Engineering, 9(11), pp. 3524-3529.

[5] Von Leipzig, K. \& Dimitrov, D. 2015. Cluster development in the SA tooling industry. The South African Journal of Industrial Engineering, 26(3), pp. 110-124.

[6] Schuh, G., Boos, W., Pitsch, M., Salmen, M., Hensen, T., Kuhlmann, T. \& Rittstieg, F. 2015. Fast forward tooling, pp. 40-43. Retrieved October 13, 2016 from https://werkzeugbau-akademie.de/wpcontent/uploads/sites/17/2015/06/Study-Fast-Forward Tooling.pdf

[7] Oesterreich, T.D. \& Teuteberg, F. 2016. Understanding the implications of digitisation and automation in the context of Industry 4.0: A triangulation approach and elements of a research agenda for the construction industry. Computers in Industry, 83, pp. 121-139.

[8] Schuh, G., Pitsch, M., Salmen, M. \& Rittstieg, F. 2016. Fast forward tooling. Proceedings of International Conference on Competitive Manufacturing 16, pp. 63-70. Stellenbosch, South Africa.

[9] Samuelson, N., Lanman, C. \& Pocek, C. 2015. Internet of Things: New challenges and opportunities for semiconductor supply chain. INSIGHT, pp. 1-3.

[10] Schuh, G., Kuhlmann, K., Pitsch, M. \& Komorek, N. 2013. Digitalization as a key enabler for efficient value creation networks in the tool and die making industry. Proceedings of Portland International Conference on Management of Engineering and Technology. Technology Management in the IT-Driven Services, pp. 1976-1984.

[11] Stolterman, E. \& Fors, A.C. 2004. Information technology and the good life. Information Systems Research, 143, pp. 687-692.

[12] Parviainen, P., Tihinen, M., Kääriäinen, J. \& Teppola, S. 2017. Tackling the digitalization challenge: How to benefit from digitalization in practice. International Journal of Information Systems and Project Management, 5(1), pp. 63-77.

[13] Brennen, S. \& Kreiss, D. 2014. Digitalization and digitization. Retrieved September 12, 2017, from http: / /culturedigitally.org/2014/09/digitalization-and-digitization/ 
[14] Park, J. 2015. Evaluating a mobile data-collection system for production information in SMEs. Computers in Industry, 68, pp. 53-64.

[15] Henriette, E., Feki, M. \& Boughzala, I. 2015. The shape of digital transformation: A systematic literature review. Proceedings of Mediterranean Conference on Information Systems (MCIS), Pp. 1-13. Samos, Greece: Association for Information Systems.

[16] Reinhard, G., Jesper, V. \& Stefan, S. 2016. Industry 4.0: Building the digital enterprise. 2016 Global Industry 4.0 Survey, pp. 1-39.

[17] Doukas, C. 2012. Building the Internet of Things with the Arduino. USA: CreateSpace Independent Publishing Platform.

[18] Ray, P.P. 2016. A survey of IoT cloud platforms. Future Computing and Informatics Journal, 1(1-2), pp. 35-46.

[19] Lamont, J. 2017. IoT platforms create value in connectivity. KM World, 26(3), p. 3.

[20] Trucano, M. 2014. Using mobile phones in data collection: Opportunities, issues and challenges. [Online], Retrieved September 10, 2015: http://blogs.worldbank.org/edutech/using-mobile-phones-datacollection-opportunities-issues-and-challenge.

[21] Vieira, D. \& Vieira, D. 2015. Empowering mobile users: Applications in mobile data collection.

[22] Jung, C. 2011. Mobile data collection systems: A review of the current state of the field. Retrieved from http://humanitarian-nomad.org/mdc-research/.

[23] Satterlee, E., McCullough, L., Dawson, M. \& Cheung, K. 2015. Paper-to-mobile data collection: A manual. Retrieved August 28, 2016 from

https://www.fhi360.org/sites/default/files/media/documents/Paper_to_Mobile_Data_Collection_Manual 1.0.pdf.

[24] Elvins, T.T. \& Todd, T. 1998. Augmented reality. ACM SIGGRAPH Computer Graphics, 32(1), pp. 11-13.

[25] Chandra, P. 2016. Nanobiosensors for personalized and onsite biomedical diagnosis. Stevenage, England: The Institute of Engineering and Technology.

[26] Abbasi, Q.H., Ur-Rehman, M., Qaraqe, K. \& Alomainy, A. 2016. Advances in body-centric wireless communication: Applications and state-of-the-art. Stevenage, England: The Institute of Engineering and Technology.

[27] PR Newswire. 2016. Office of the future - Part 1: Wearables and augmented reality. Retrieved October 09, 2017 from https://search-proquest-com.ez.sun.ac.za/docview/1803835661?rfr_id=info\%3Axri\%2Fsid\%3Aprimo

[28] Newman, N.J. \& Clark, A.F. 1999. Sulawesi: A wearable application integration framework, in The Third International Symposium on Wearable Computers (pp. 170-171). San Francisco, California: IEEE Computer Society.

[29] Mell, P. and Grance, T. 2011. The NSIT definition of cloud computing: Recommendations of the National Institute of Standards and Technology. Retrieved 10 July 2016 from http://faculty. winthrop.edu/domanm/csci411/Handouts/NIST.pdf.

[30] Carretero, J. \& Blas, J.G. 2014. Introduction to cloud computing: Platforms and solutions. Cluster Computing, 17(4), pp. 1225-1229.

[31] Jennings, R. 2009. Cloud computing with the Windows Azure platform. Retrieved August 24, 2014 from http: / /lib.myilibrary.com.ez.sun.ac.za/Open.aspx?id=230684.

[32] Shroff, G. 2010. Enterprise cloud computing: Technology, architecture, applications. Cambridge, UK: Cambridge University Press.

[33] Hung, M.H., Lin, Y.C., Quoc Huy, T., Yang, H.C. \& Cheng, F.T. 2012. Development of a cloud-computingbased equipment monitoring system for machine tool industry. Proceedings of International Conference on Automation Science and Engineering (pp. 962-967).

[34] Choi, Y., Shin, J., Choi, H. \& Lee, S. 2010. Quality management system for web-based collaboration in mold \& die industry. Proceedings of 40th International Conference on computers and industrial engineering: Soft computing techniques for advanced manufacturing and service systems, pp. 1-6. Awaji, Japan: Institute of Electronics and Electrical Engineers.

[35] Silva, C., Roque, L. \& Almeida, A. 2006. MAPP: A web-based decision support system for the mould industry. Decision Support Systems, 42, pp. 999-1014.

[36] Li, M., Wang, J., San, Y. \& Seng, K. 2005. A collaborative application portal for the mould industry. International Journal of Production Economics, 96, pp. 233-247.

[37] Meuter, M.L., Bitner, M.J., Ostrom, A.L. \& Brown, S.W. 2005. Choosing among alternative service delivery modes: An investigation of customer technologies. Journal of Marketing, 69(2), pp. 61-83.

[38] Meuter, M.L., Ostrom, A.L., Roundtree, R.I. \& Bitner, M.J. 2000. Self-service technologies: Understanding customer satisfaction with technology. Journal of Marketing, 64(3), pp. 50-64.

[39] Rajaraman, V. 2016. Big data analytics. Resonance, 21(8), pp. 695-716.

[40] Shahriar, A., Wamba, S.F., Gunasekaran, A., Dubey, R. \& Childe, S. 2016. How to improve firm performance using big data analytics capability and business strategy alignment. International Journal of Production Economics, 182, pp. 113-131.

[41] Zhong, R.Y., Xu, C., Chen, C. \& Huang, G.Q. 2017. Big data analytics for physical Internet-based intelligent manufacturing shop floors. International Journal of Production Research, 55(9), pp. 2610-2621.

[42] Yichuan, W. \& Nick, H. 2017. Exploring the path to big data analytics success in healthcare. Journal of Business Research, 70, pp. 287-299.

[43] Zhenning, X., Frankwick, E. \& Ramirez, G. 2016. Effects of big data analytics and traditional marketing analytics on new product success: A knowledge fusion perspective. Journal of Business Research, 69(5), pp. 1562-1566. 
[44] Meijer, G.C.M. (ed.). 2008. Smart sensor systems. West Sussex, UK: J. Wiley \& Sons, Ltd.

[45] Moreu, F. 2017. Railroad bridge monitoring using wireless smart sensors. Structural Control, 24(2), p. 17.

[46] Nihtianov, S. 2017. New trends in smart sensors for industrial applications: Part I. IEEE Transactions on Industrial Electronics, 64(9), p. 3.

[47] Acho, L. 2017. Event-driven observer-based smart-sensors for output feedback control of linear systems. Sensors (14248220), 17(9), p. 11.

[48] Gaggioli, A., Pioggia, G., Tartarisco, G., Baldus, G., Corda, D., Cipresso, P. \& Riva, G. 2013. A mobile data collection platform for mental health research. Personal and Ubiquitous Computing, 17(2), pp. 241251.

[49] Nambiar, A.N. 2009. RFID technology: A review of its applications. Proceedings of the World Congress on Engineering and Computer Science, 2, pp. 20-22.

[50] Ting, S.L., Tsang, A.H.C. \& Tse, Y.K. 2013. A framework for the implementation of RFID systems. International Journal of Engineering Business Management, 5(9), pp. 1-16.

[51] Welbourne, E., Battle, L., Cole, G., Gould, K., Rector, K., Raymer, S. \& Balazinska, M. 2009. Building the Internet of Things using RFID. Internet Computing, IEEE, 13(3), pp. 48-55.

[52] Barenji, A.V, Barenji, R.V \& Hashemipour, M. 2014. A framework for structural modelling of an RFIDenabled intelligent distributed manufacturing control system. South African Journal of Industrial Engineering, 25(2), pp. 48-66.

[53] Zhong, R.Y., Dai, Q.Y., Qu, T., Hu, G.J. \& Huang, G.Q. 2013. RFID-enabled real- time manufacturing execution system for mass-customization production. Robotics and Computer-Integrated Manufacturing, 29(2), pp. 283-292.

[54] Teramoto, K. \& Onosato, M. 2001. In-process visualization of machining state with sensor-based simulation to support the recognition ability of operators. International Conference on Machine Automation, 27-29 September 2000, Osaka Japan, pp. 389-394.

[55] Inoue, K., Okuda, A., Tani, H. \& Mae, Y. 2001. Distributed control of hyper-redundant manipulator with expansion and contraction motion for obstacle avoidance. International Conference on Machine Automation, 27-29 September 2000, Osaka Japan, pp. 315-320.

[56] Jeong, J.W., Yeo, W.H., Akhtar, A., Norton, J.J.S., Kwack, Y.J., Li, S., Jung, S.Y., Su, Y. \& Rogers, J.A. 2013. Materials and optimized designs for human-machine interfaces via epidermal electronics. Advanced Materials, 25(47), pp. 6839-6846.

[57] Summers, B.J. 2009. Fraud containment. Economic Perspectives, 23(1), pp. 17-21.

[58] Bignell, K.B. 2006. Authentication in an Internet banking environment: Towards developing a strategy for fraud detection. Proceedings of International Conference on Internet Surveillance and Protection, p. 23. Cap Esterel, France: The Institute of Electrical and Electronics Engineers.

[59] News Bites. 2014. CA technologies helps card issuers combat fraud and increase revenue with nextgeneration authentication solution. Retrieved March 13, 2015 from http://files.shareholder.com/downloads/CA/0x0x784047/0AB4E36B-07B2-4900-95C57DC94DBC6501/CA_News_2014_9_30_Corporate.pdf

[60] Honiball, J.R. 2010. The application of 3D printing in reconstructive surgery (doctoral dissertation, University of Stellenbosch, South Africa). Retrieved from http://scholar.sun.ac.za/handle/10019.1/4207.

[61] Long, Y., Pan, J., Zhang, Q. \& Hao, Y. 2017. 3D printing technology and its impact on Chinese manufacturing. International Journal of Production Research, 55(5), pp. 1488-1497.

[62] Christensen, A. \& Rybicki, F.J. 2017. Maintaining safety and efficacy for 3D printing in medicine. 3D Printing in Medicine, 3(1), p. 1.

[63] Hirsch, J.D., Vincent, R.L. \& Eisenman, D.J. 2017. Surgical reconstruction of the ossicular chain with custom 3D printed ossicular prosthesis. 3D Printing in Medicine, 3(1), p. 7.

[64] Leng, S., McGee, K., Morris, J., Alexander, A., Kuhlmann, J., Vrieze, T., McCollough, C.H. \& Matsumoto, J. 2017. Anatomic modeling using 3D printing: Quality assurance and optimization. 3D Printingin Medicine, 3(1), p. 6.

[65] Costa, M.O., Nosach, R. \& Harding, J.C.S. 2017. Development of a 3D printed device to support long term intestinal culture as an alternative to hyperoxic chamber methods. 3D Printing in Medicine, 3(1), p. 9.

[66] Radenkoic, D., Solouk, A. \& Seifalian, A. 2016. Personalized development of human organs using 3D printing technology. Medical Hypotheses, 87, pp. 30-33.

[67] Ebner, G., Buvat, J., Schneider-Maul, R., Kvj, S. \& Klade, W. 2013. Operational excellence through digital in manufacturing industries. Capgemini Consulting Group, pp 1-15.

[68] Hold, P. and Sihn, W. 2016. Towards a model to identify the need and the economic efficiency of digital assistance systems in cyber-physical assembly systems, in International Workshop on Cyberphysical Production Systems at CPS Week 2016, Vienna, Austria, IEEE.

[69] Krüger, J., Lien, T.K., and Verl, A. 2009. Cooperation of human and machines in assembly lines, in CIRP Annals 2009, pp. 628-646.

[70] Hinrichsen, S., Riedieger, D. and Unrau, A. 2016. Assistance systems in manual assembly. Proceedings of 6th International conference on Production Engineering and Management, 29 September 2016, Villmer Lemgo, Germany, pp. 3-14.

[71] Reisinger, G., Komenda, T., Hold, P. \& Sihn, W. 2018. A concept towards automated data-driven reconfiguration of digital assistance systems, Procedia Manufacturing, 23, pp. 99-104, ISSN 2351-9789, https://doi.org/10.1016/j.promfg.2018.03.168.

[72] Yang X. \& Plewe D.A. 2016. Assistance systems in manufacturing: A systematic review, in Schlick C., Trzcieliński S. (eds), Advances in ergonomics of manufacturing: Managing the enterprise of the future. Advances in Intelligent Systems and Computing, Vol 490. Springer, Cham, pp. 279-289. 
[73] Dewa, M., Matope, S., van der Merwe, A.F., Nyanga, L. \& Garikayi, T. 2013. An analysis of methodologies for agent-based modeling for e-manufacturing systems in South Africa. International Journal of Advances in Mechanical and Automobile Engineering, 1(1), pp. 73-78.

[74] Oks, S.J., Fritzche, A. \& Lehmann, C. 2016. The digitalisation of industry from a strategic perspective. Proceedings of Research and Development Management Conference 2016, From Science to Society: Innovation and Value Creation, 3-6 July, Cambridge, United Kingdom, pp. 1-9.

[75] Monostori, L. 2014. Cyber-physical production systems: Roots, expectations and research and development challenges, Procedia CIRP, 17, pp. 9-13.

[76] Hannola, L., Steinhuser, M., Richter, A., Schafler M., \& Laceuva-Perez, F. 2018. Assessing the impact of digital interventions on shop-floor workers. Proceedings Conference: 20th International Working Seminar on Production Economics: Innsbruck, Austria.

[77] Hold, P., Erol, S., Reisinger, G. \& Sihn, W. 2017. Planning and evaluation of digital assistance systems. Proceedings of the 7th Conference on Learning Factories, CLF, Procedia Manufacturing 9(2017), pp. 143150.

[78] Geiser, G. 1997. Information technology work design, in Luczak, H. \& Volpert, W. (eds), Handbuch Arbeitswissenschaft. Stuttgart: Schäffer-Poeschel, pp. 589-594.

[79] Wiesbeck, M., Zaeh, M.F., Rudolf, H. \& Vogl, W. 2006. New media and technology support in manual assembly, in Fischer, X., et al. (eds), Research in Interactive Design: Proceedings of Virtual Concept 2006, Playa Del Carmen / Mexico, Paris, Springer, 2006.

[80] Ho, Y., Yamaguchi, T., Kawagishi, Y., Sato-Shimokawara, E. \& Tagawa, N. 2013. Construction of user model for an assistance system with sensor network, IECON 2013: 39th Annual Conference of the IEEE Industrial Electronics Society, Vienna, 2013, pp. 8265-8270. doi: 10.1109/IECON.2013.6700517.

[81] Kleineberg, T., Eichelberg, M. \& Hinrichsen, S. 2017. Participative development of an implementation process for worker assistance systems. Proceedings of 7th International Conference on Production Engineering and Management, 27-29 September 2017, Publication Series in Direct Digital Manufacturing, editors: E. Padoano \& F.J. Villmer, Pordenone, Italy. Volume: 7, pp. 25-26.

[82] Landau, K. 2002. The development of driver assistance systems following usability criteria. Journal of Behavioural Information Technology, 21(5), pp. 341-344.

[83] Ziefle, M. \& Rocker, C. 2009. Human-centred design of e-health technologies: Concepts, methods and applications. Niagara Falls: IGI Publications.

[84] Rocker, C. 2013. User-centred design of intelligent environments: Requirements of designing successful ambient assisted living systems. Proceedings of Central European Conference of Information and Intelligence Systems (CECIIS’13), Varazdin, Croatia, pp. 4-11.

[85] Hold, P., Ranz, F., Sihn, W. \& Hummel, V. 2016. Planning operator support in cyber-physical system assembly. IFAC-PapersOnLine, 49, pp. 60-65.

[86] Zaeh, M.F., Wiesbeck, M., Engstler, F., Friesdorf, F., Schubo, A., Stork, S., Bannat, A. \& Wallhoff, F. 2007. Cognitive work systems in the assembly: Adaptive assembly guidance using condition-based, environment-dependent statement generation, in ZWF Journal for Economical Factory Operation, 2007, pp. 644-650.

[87] Korn, 0. 2014. Context-aware assistive systems for augmented work: A framework using gamification and projection, (Doctoral Dissertation, University of Stuttgart, Germany).

[88] Lusic, M., Fischer, C., Bonig, J., Hornfeck, R. \& Franke, J. 2016. Worker information systems: State of the art and guideline for selection under consideration of company specific boundary conditions. Proceedings of 48th CIRP Conference on Manufacturing Systems, Procedia CIRP 41, pp. 1113-1118.

[89] Krishnan, A., Pujari, G. \& Sarkar, N. 2015. A framework to speed manufacturing's digital business transformation, pp. 1-17. Retrieved April 18, 2016 from

https: / /www.cognizant.com/whitepapers/A-Framework-to-Speed-Manufacturings-Digital-BusinessTransformation-codex1614.pdf

[90] Lucas, P. \& van der Gaag, L. 1991. Principles of expert systems. Retrieved May 16, 2016 from http://dl.acm.org/citation.cfm?id=132689.

[91] Hall, J.G. 2012. Engineering knowledge engineering. Expert Systems, 29(5), pp. 427-428.

[92] Brown, A. \& Danaher, P.A. 2017. CHE principles: Facilitating authentic and dialogical semi-structured interviews in educational research. International Journal of Research \& Method in Education, 40, pp. 115.

[93] Dewa, M.T., van der Merwe, A.F., Matope, S. \& Nyanga, L. 2016. Decision support heuristics for cost estimation model of injection moulds. Proceedings of 27th SAIIE Conference (pp. 163-175). Stonehenge, North West: South African Institute for Industrial Engineering.

[94] Fonseca M.J., Henriques E., Ferreira A. \& Jorge J. 2007. Assisting Mould Quotation Through Retrieval Of Similar Data. In: Cunha P.F., Maropoulos P.G. (eds) Digital Enterprise Technology. Springer, Boston, MA.

[95] Duverlie, P. \& Castelain, J.M. 1999. Cost estimation during design step: Parametric method versus case based reasoning method. The International Journal of Advanced Manufacturing Technology, 15(12), pp. 895-906.

[96] Denkena, B., Lorenzen, L.E. \& Schürmeyer, J. 2009. Rule-based quotation costing of pressure die casting moulds. Production Engineering, 3(1), pp. 87-94.

[97] Dewa, M.T., van der Merwe, A.F. \& Matope, S. 2016. A holonic approach to reactive scheduling when rush orders emerge. Proceedings of International Conference on Competitive Manufacturing 16, pp. 337341. Stellenbosch, South Africa. 
[98] Dewa, M.T., van der Merwe, A.F. \& Matope, S. 2015. Holonic control system: Reference design architecture for South African tooling industrial clusters. Proceedings of 45th Conference on Computers and Industrial Engineering (CIE 45), pp. 1-8. Metz, France.

[99] Dewa, M.T., van der Merwe, A., Matope, S. \& Nyanga, L. 2014. An empirical analysis of operational disturbances and their impact on business performance in manufacturing firms: Case tooling industry South Africa. Proceedings of 26th SAIIE Conference, pp. 1-14. Muldersdrift, South Africa: Southern African Institute for Industrial Engineering.

[100] Wyns, J. 1999. Reference architecture for holonic manufacturing systems: The key to support evolution and reconfiguration (Masters thesis, Katholieke Universiteit Leuven, Belgium).

[101] Dewa, M., van der Merwe, A.F. \& Matope, S. 2018. Digitalisation of shop-floor operations in the South African tool, die and mould-making industry. South African Journal of Industrial Engineering, 29(2), pp. 153-170. 